\title{
Establishing the 'Historical Dictionary of Switzerland': an authoritative new source for the historiography of science in Switzerland
}

\author{
Erwin Neuenschwander ${ }^{\bullet}$
}

\begin{abstract}
The Historical Dictionary of Switzerland (HDS) covers the history of humankind in the geographical area of today's Switzerland from the very beginning in Paleolithic times up to the twenty-first century. The HDS comprises articles in four broad categories: biographies $(35 \%)$, articles on families and genealogy $(10 \%)$, geographical entries $(30 \%)$ and articles on thematic contributions (25\%). The HDS was published in parallel in each of the three major Swiss national languages German, French, and Italian from 2002 to 2014. Each edition comprises 13 volumes of about 10,000 pages. In 1997, the HDS Board of Trustees decided to commemorate the 150th anniversary of the founding of the Swiss Confederation in 1848 with an internet publication of the HDS, which was simultaneously being published and which will now be augmented by multimedia and linked data (cf. www.hls-dhs-dss.ch). Our contribution describes the complex editorial processes of the whole subject area of mathematics and natural sciences in the HDS-covering about 1,200 biographies and approximately 40 thematic articles-supervised by the author and his working group in the years 1994-2014. As a trained mathematician and historian of science, and as scientific advisor for the HDS's entire subject area of mathematics and the natural sciences, I wrote this article with the aim of sharing my experiences in representing the history of science in a general historical encyclopedia. The processes described below may perhaps be useful to other natural scientists or proper historians who intend to undertake similar projects.
\end{abstract}

\section{Keywords}

Digital humanities; Swiss reference resources; Swiss historical information network; Bibliography and documentation, Biography

\footnotetext{
- Institute of Mathematics, University of Zurich, Switzerland. $₫$ neuenschwander@math.uzh.ch. This article is a slightly shortened (although in respects of future developments of the HDS extended) version of a report on twenty years of editorial work at the HDS, which will appear in German as an appendix to Erwin Neuenschwander, ed., Enzyklopädie zur Geschichte der Naturwissenschaften in der Schweiz (Basel: Schwabe 2018/19). Parts of it were first presented at the symposium "Prosopography and the History of Science in a Networked Computational Environment" at the $7^{\text {th }}$ International Conference of the European Society for the History of Science in Prague in 2016, and at the 2016 HSS Annual Meeting in Atlanta, USA. In summer 2017, I gave a talk about the same topic within the symposium "Doing History of Science in a Digital, Global, Networked Community" at the $25^{\text {th }}$ International Congress of History of Science and Technology in Rio de Janeiro. For further details about the editorial correspondence and archival documents used, I refer the reader to the above-mentioned Germanlanguage publication. I would like to express my gratitude to Alice Koller, Philip Beeley, Martin Kurz and William Shea for helping to improve substantially the English language version. Nevertheless, responsibility for any remaining mistakes remains entirely with me as author.
} 


\section{Some brief remarks on the prehistory, conception and scope of the Historical Dictionary of Switzerland (HDS)}

Until the beginning of the twenty-first century, only a small number of encyclopedias had been published in Switzerland. These few nevertheless were always politically significant, because Switzerland is a quadrilingual country: its four linguistically different regions encompass various cultural and religious traditions. The importance of historical dictionaries arose because, more than once, Switzerland forged and defined itself by reference to its history.

The first well-known comprehensive Swiss lexicon was the Allgemeines Helvetisches, Eydgenössisches, oder Schweitzerisches Lexicon (General Helvetic, Confederate, or Swiss Lexicon), published by the mayor of the city of Zurich, Johann Jacob Leu (1689-1768). This lexicon in twenty volumes appeared during the Enlightenment from 1747 through to 1765, and was funded by the author (Figure 1$)^{1}$

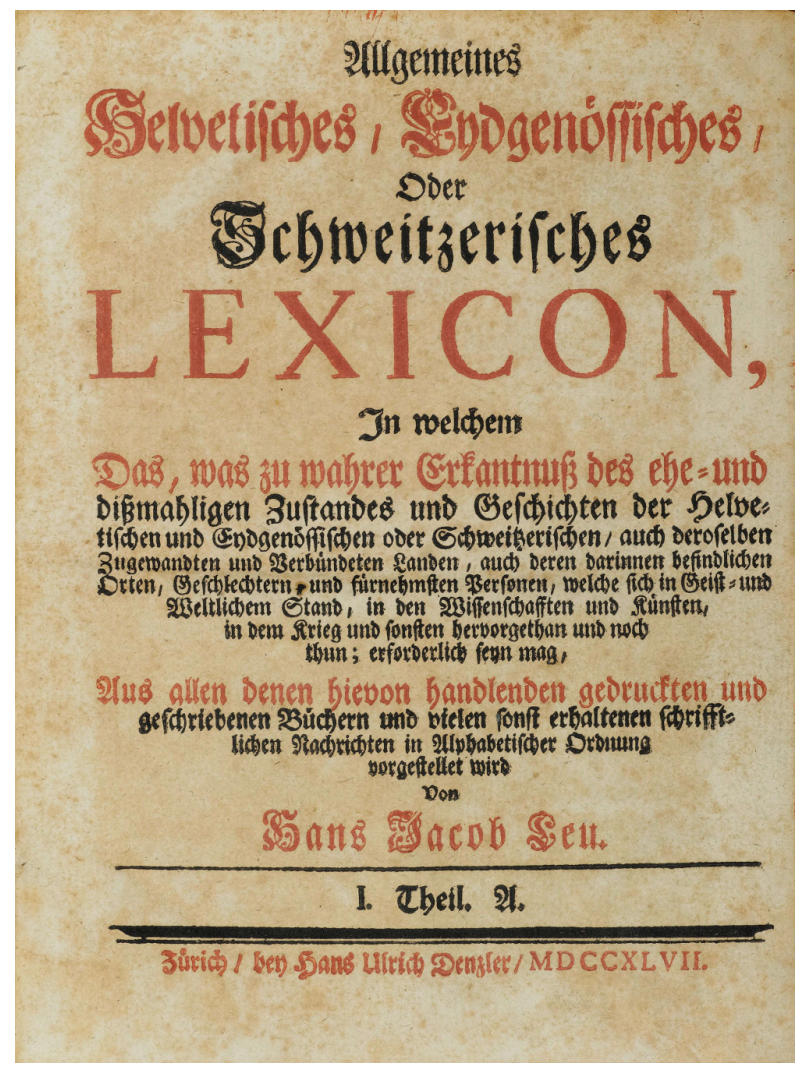

Fig. 1. Title page of part one of the first general Swiss Lexicon by Johann Jakob Leu (Allgemeines Helvetisches, Eydgenössisches, oder Schweitzerisches Lexicon, vol. 1, part 1

[Zürich: Hans Ulrich Denzler, 1747])

\footnotetext{
${ }^{1}$ Concerning Johann Jacob Leu, see the corresponding article in the Historical Dictionary of Switzerland (HDS). Printed publications: Historisches Lexikon der Schweiz (HLS)/ Dictionnaire historique de la Suisse (DHS)/ Dizionario storico della Svizzera (DSS), 13 vols. (Basel/Hauterive/Locarno: Schwabe/Attinger/Dadò, 2002-2014); website: http://www-hls-dhs-dss.ch.
} 
It was followed by the seven-volume Historisch-Biographisches Lexikon der Schweiz (Historical-Biographical Dictionary of Switzerland) after the First World War, in the years from 1921 through to 1934. This bilingual lexicon-in German and in French - was printed by Victor Attinger, a publishing house in Neuchâtel, which lies in the French-speaking part of Switzerland. There were also some specialized or minor encyclopedias: the six-volume Geographisches Lexikon der Schweiz (Geographical Lexicon of Switzerland) appeared shortly after the turn of the twentieth century, from 1902 to 1910-also in German and in Frenchand was also published by Attinger in Neuchâtel. Just after the Second World War there appeared a more encyclopedic than genuinely historically oriented seven-volume Schweizer Lexikon (Swiss Lexicon) (1945-1948). It was followed by the similarly oriented six-volume Schweizer Lexikon 91 (Swiss Lexicon 91) (1991-1993), which appeared on the occasion of the seventh centenary of the Swiss confederacy. ${ }^{2}$

The call for an updated or completely new edition of the above-mentioned HistoricalBiographical Dictionary of Switzerland (HBLS), which for decades had served as the main historical reference work, began to be heard already in the 1950s. However, all initiatives were bogged down: high costs were feared as well as an unseemingly long time for the undertaking. Finally, in 1982 the present Swiss Academy of Humanities and Social Sciences (abbreviated in German as SAGW) agreed to draw up a proposal for the project. The working group consisted of three scholars: Carl Pfaff, Professor of medieval studies at the (bilingual) University of Fribourg; Alain Dubois, Professor of Swiss history at the University of Lausanne in the French speaking part of Switzerland; and Fritz Glarner, the Head of the State Archives of Lucerne. The group commissioned the young Swiss historian Marco Jorio-subsequently editor-inchief of the HDS - to draft a feasibility study, which Dr. Jorio completed during the years 1985 through to $1987^{3}$. Even before the SAGW received the final report, the Academy submitted its own proposal with a request for a subsidy to the Federal Government in March 1987. Both Chambers of the Federal Parliament approved the proposal without opposition in the same year, and a first global credit was granted based on the Federal Law on Research.

The concept presented in 1987 to the Federal Government could be maintained in its basic outline until the publication of the final volume in 2014. The HDS was designed as an encyclopedic academic lexicon consisting of about 36,000 articles that would set forth the entire Swiss history on a scholarly basis and in an easily accessible form. Like its predecessor, the Historical-Biographical Dictionary of Switzerland, the HDS encompasses four different categories of articles, which cover the following amounts of space: subject articles (25 percent), articles about Swiss townships and geographical entities (30 percent), Swiss families (10 percent), and biographies (35 percent). Twenty percent of line-space was reserved for relevant images and diagrams. In order to meet the compelling claims of culture, language policy, and federal policy on cohesion, the lexicon appeared simultaneously in three equivalent editions in the three major languages of Switzerland. Our fourth national language, Rhaeto-Romanic,

\footnotetext{
${ }^{2}$ For additional details about the historical dictionaries that appeared in Switzerland, see the article "Lexika" in the HDS as well as the catalogue of the exhibition in 2008/09 in the Swiss National Library edited by Cindy Eggs and Marco Jorio, entitled Am Anfang ist das Wort: Lexika in der Schweiz (Baden: hier+jetzt, 2008), which includes articles in German, French, and Italian.

${ }^{3}$ Cf. Marco Jorio, Das Historische Lexikon der Schweiz: Schlussbericht der Projektierungsphase 1.4.1985-31.3.1987 (Bern: Schweizerische Akademie der Geisteswissenschaften, Arbeitsgruppe HLS, 1987); unpublished report available at the Swiss National Library or the Swiss Federal Archives.
} 
which is spoken in the Grisons in the southeast of Switzerland, and the distinctive culture of its inhabitants, are represented by a supplemental two-volume partial edition in that language, with additional indexes in German and Italian. With its four parallel editions, the HDS is unique among national encyclopedias, at least as far as we know (Figure 2). ${ }^{4}$

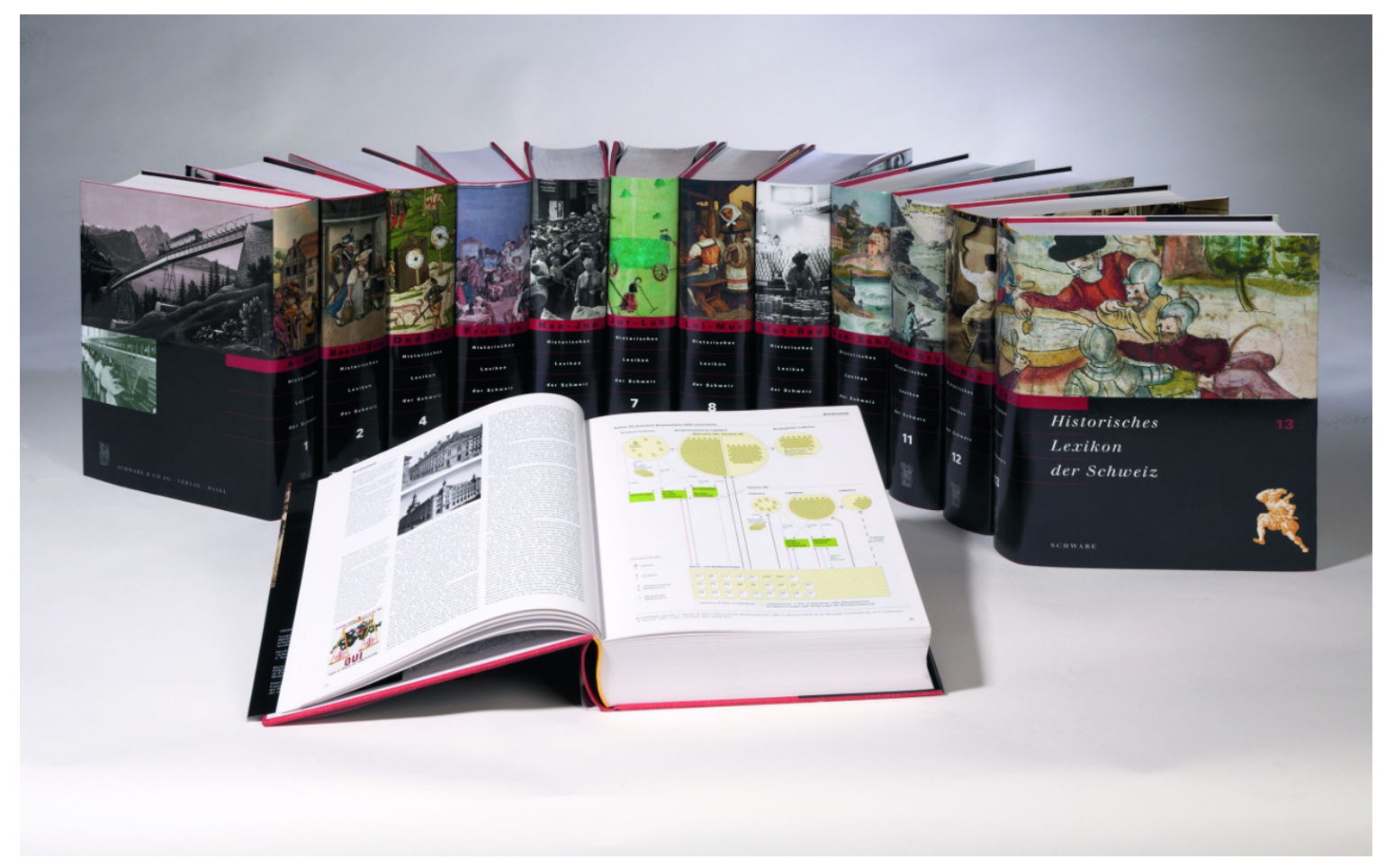

Fig. 2 The thirteen volumes of the German print edition of the Historical Dictionary of Switzerland (Historisches Lexikon der Schweiz, 13 vols. [Basel: Schwabe, 2002-2014])

The HDS follows the lexicographic principle of "relative completeness," i.e. comprehensive information about Swiss history is guaranteed in a certain measure. The importance of a subject or a person from the present point of view is the decisive factor for the length of an article. However, the intensity and the current state of research on a certain subject, and how well it is lexicographically accessible are also taken into account. Therefore, the great figures of Swiss history are covered in less space than usual, whereas lesser known persons and themes get more space, within reasonable limits. The HDS reflects newly developed research areas and methods, and the paradigm change in historical research over the past decades. This means above all more emphasis on social, cultural and economic history. New subjects or persons have been introduced that are rarely if at all to be found in earlier historical dictionaries.

\footnotetext{
${ }^{4}$ According to the preface of the German edition of the HDS, which also served as a basis for the five subsequent paragraphs.
} 
The structuring and realization of the HDS has proved to be enormously difficult, as had been foreseen by the above-mentioned SAGW working group in its final report in 1987, and by earlier initiators. The absence of a continuous tradition in Switzerland in the area of lexicography, the lack of experience in building a tri- and even quadrilingual lexicon, the scarce human resources regarding authors, scientific editors, and translators, but above all the varying level of Federal subsidies contributed to slowing down progress.

The HDS staff was composed of approximately thirty persons at the central editorial office (Zentralredaktion) and roughly a hundred scientific advisors (wissenschaftliche Berater) who teach and do research at Swiss or foreign universities or at our numerous cantonal (state) archives. A separate editorial team was responsible for each of the four language editions. The team for the German and French editions were located in Berne, the Italian language team in Bellinzona in the Italian part of Switzerland, and the Rhaeto-Romanic team in Chur, the capital of the Grisons. Other members of the central editorial office were responsible for the illustrations, information technology, and logistics. More than 2,500 qualified historians wrote the articles, and over 100 specialists subsequently translated them into the other two languages. The total costs of the project have reached about 100 million Swiss francs.

In 1988, the editorial board began-supported by the scientific editors - to create the list of keywords, which was revised several times and finished only seven years later in 1995. The computer system was set up step by step from 1989 onward. It enabled the compilation and editorial supervision of the HDS directly on the computer in all production phases, from entering a keyword to managing all the steps of editing the texts and preparing them for printing. After a testing period, the first articles began to be assigned to the authors in 1991. In 1997, the HDS Board of Trustees decided to give priority to the online publication (released in 1998), which initially had been planned to come only later, and to postpone the printed version until after 2000. They made this difficult decision because two of the three publishing houses withdrew their commitment as a result of a strategic reorientation due to the steadily spreading digital revolution. Finally, in 2000 the printing preparations began, which proved to be highly challenging, because the HDS-database had to be converted into typeset.

Philipp von Cranach, who headed the team of the German edition, wrote in his preface to the HDS that about 70 percent of the articles were written in German. The remaining 25 percent of the articles of the German edition were translated from texts written originally in French, and about 5 percent were translated from Italian. Translating the original articles into the two other national languages proved to be extremely difficult because qualified translators for historical texts were scarce, even in multilingual Switzerland, and a totally new terminology had sometimes to be invented. Furthermore, the editorial board had to deal with problems of updating and with the dilemma that the HDS was, on the one hand, a lexicon written by its authors and, on the other hand, considered itself as service provider for academia. In order to assist the reader within the limits of scarce line-space with a new bibliographical reference, the editorial board added sometimes titles to the bibliographies, which the author could not yet have known at the time of writing the article. 


\section{Establishing contacts with the HDS, setting up of the keyword lists, and building of expert groups in the natural sciences}

According to my records, my first contact with the HDS goes back to September 1994. I asked the editor-in-chief Marco Jorio at the suggestion of my long-time friend Heinz Balmer, scientific advisor of the HDS for the natural sciences in the nineteenth and twentieth centuries, whether I could take on the articles of the mathematicians and astronomers Jost Bürgi, Ludwig Schläfli, and Charles François Sturm, which I had already written for the Schweizer Lexikon 91 ("Swiss Lexicon 91"). A few days later, Balmer wrote to me highly delighted, saying that chief editor Jorio had agreed to the proposal. On behalf of Jorio, he also asked me to take on the subject article "mathematics" and additionally, up to January 1995, create a list of those mathematicians still missing that undoubtedly needed to be included. ${ }^{5}$ It should contain a maximum of eighty Swiss mathematicians born before 1930. Balmer also showed in his letter a certain disappointment because for the main subject articles in science, i.e. those about mathematics, astronomy, physics, etc., the HDS had only foreseen approximately one to two pages. Nevertheless, he believed that this could still be remedied in the future, and recommended that I write the articles "in such a manner that I could take responsibility for the contents."

As the first volume of the HDS was only to appear in 2002, I started with the set-up of the desired control list and list of additions to the subject area of mathematics. This proved to be quite an elaborate and difficult task, because the mathematicians - that had already been included in the HDS-were sometimes allocated to different subject fields. There existed, apart from the field of the "natural sciences in the 19th and 20th centuries," which was supervised by Balmer, also a subject field called "education (high schools, universities up to 1800)," which was later renamed "enlightenment, history of science of the early modern period)," 6 to which were assigned nearly all pre-1800 mathematicians, for example the Bernoullis and Euler. Others, for instance Hermann Weyl and Heinz Hopf, were included in fields that were called "engineers/technicians," or "technology," or "cultural history of French-speaking Switzerland 17th/18th centuries," or "even in the Catholic church." This complicated the setting up of a comprehensive list consisting of all the mathematicians already included in the HDS. It also made matters difficult, when articles had to be assigned to authors, as well as in the course of the scientific review and editing process.

Having compiled the list of the mathematicians already selected by the HDS, I set to work on the review of earlier relevant lexicons and encyclopedias, to find further mathematicians worthy of inclusion. I searched the above-mentioned Schweizer Lexikon 91 (SL), the Neue Deutsche Biographie (NDB) ("New German Biography"), the Dictionary of Scientific Biography (DSB), the Lexikon bedeutender Mathematiker ("Lexicon of Eminent

\footnotetext{
5 For my earlier work on the history of mathematics in Switzerland see Erwin Neuenschwander, "Zur Historiographie der Mathematik in der Schweiz," Archives Internationales d'Histoire des Sciences 49 (1999): 369-99; and Erwin Neuenschwander, "Switzerland," in Writing the History of Mathematics: Its Historical Development, ed. Joseph W. Dauben, \& Christoph J. Scriba, (Basel: Birkhäuser Verlag, 2002), 97-107 [abbreviated English version of Neuenschwander 1999].

${ }^{6}$ The naming system of the subject fields varied in the course of time. The above-mentioned subject field was at times named "education and intellectual history of the early modern period" ("Bildung und Geistesgeschichte der frühen Neuzeit") and in internal documents abbreviated as "scholars EMP" ("Gelehrte FNZ").
} 
Mathematicians") by S. Gottwald, H.-J. Ilgauds and K.-H. Schlote and the still rewarding and rich Biographien zur Kulturgeschichte der Schweiz ("Biographies about Cultural History of Switzerland") by the Swiss astronomer and historian of science Rudolf Wolf (1816-1893). In doing so, I simultaneously noted down the thus found occurrence of biographies also in my keyword list, with the above-mentioned initials of the sources (SL, NDB, DSB, etc.) for the purpose of the selection and later scientific revision of the articles. Mathematicians, who were generally known but not yet included, were inserted directly into my main list. Less important ones were integrated in a summary list at the end of the main one under the title "Not yet considered."

The new list drawn up in this manner was sent to a group of mathematicians interested in the history of their discipline, and to the official representatives of mathematics at the Swiss Academy of Sciences and the Swiss Mathematical Society. At the same time, I asked the members of this group to comment on the persons in the list and to add additional names considered worthy of inclusion. The expert group was composed on the principle that at least one mathematician from each Swiss university was represented on the expert panel.

The additions and deletions proposed by the experts were then added to my keyword list. In April 1995, I sent the revised list to the members of the expert panel asking them to once again choose the most important ones among the mathematicians who had not yet been included in the HDS. The experts could give values, i.e. they could choose between one or two votes for each scholar in question. After having counted the votes, the candidates with the highest numbers of votes were transmitted to the central editorial office-in accordance with the maximum number of admissions granted by the HDS-and added to the main list.

The above-mentioned procedures yielded in a first step 52 direct admissions, which I sent to the editor in chief in January 1995, as well as 39 further proposals, which I transmitted after the second vote by the expert group. The additions proved to be crucial because several leading mathematicians of the 20th century, for example Armand Borel, Beno Eckmann, Heinz Hopf, Jürgen Moser, Alexander M. Ostrowski, Georges De Rham, Bartel Leendert van der Waerden, and Hermann Weyl, had been missing from the first keywords list of the HDS, or had been attributed to another subject area.

In March 1995, my efforts regarding the keyword list led to my appointment as scientific advisor for the entire field of mathematics and astronomy. Just ten days later, my area of responsibility was enlarged further by the addition of the field of physics. At the same time, the editor in chief asked me to set up a control list for physics and astronomy as well. For that purpose, I drew up in an analogous manner an initial list of the astronomers and physicists that had already been included in the HDS. This list was updated in a similar way as the list of mathematicians outlined before. The expert panel for physics and astronomy consisted of twenty carefully selected Swiss university professors in these fields-most of them interested in the history of their discipline. As a result of the procedures described above my overall list (and in the end the HDS) was enriched by about thirty scholars-among them such eminent physicists as Friedrich Georg Houtermans, Max von Laue, and Victor Friedrich Weisskopf. 
After revising the keyword lists for mathematics, astronomy, and physics, I set to work on the scientific review and assignment of the articles to the authors beginning with the letters A to Chz, so that the first two volumes of the HDS could well have appeared on time from 1998 onwards. However, serious problems soon emerged, in so far as quite a few of the articles already drawn up were in no way sufficient in terms of scientific standards. In addition, not enough space had been foreseen for the sciences in general. The situation became even more drastically aggravated later on because of the death of the scientific advisor for the subject area "education and intellectual history of the early modern period", Professor Hans Rudolf Guggisberg, and because my friend Balmer, former advisor for the area of the natural sciences in the nineteenth and twentieth centuries resigned as a result of chronic overload and illness. This tore a hole in the scientific advisors' group of the HDS. The resignation of Balmer meant that 285 biographies remained unchecked and were at that time abandoned. The editor in chief then tried to persuade the scientific advisor for the history of medicine, Professor Urs Boschung to take over this large bundle of biographies but the latter declined and proposed instead the anthropologist Hans-Konrad Schmutz for the biological sciences, remarking that the present author could possibly step in as advisor for the non-biosciences. However, Schmutz declined, not having time to supervise the more than 500 articles formerly allotted to Guggisberg and Balmer. In the end, I was asked to take over.

The decisive factor for my willingness to take over the entire field of the natural sciences in the HDS was my involvement in the Swiss Academy of Sciences (SCNAT) and in the organizing committee of the Zurich History of Science Colloquium held from 1975 to 2011. As long-time president of the Swiss National Committee of the International Union of History and Philosophy of Science and Technology (NC IUHPST), I felt responsible to fill in the gap caused by the resignation of Balmer. Moreover, this far ranging task could not have been accomplished without the multidisciplinary support of the experts of the SCNAT and of the Zurich History of Science Colloquium, which is why I shall present both institutions briefly.

The NC IUHPST represents the SCNAT in the International Union of History and Philosophy of Science and Technology (the former IUHPS), and serves also as connecting link between the Schweizerische Gesellschaft für Geschichte der Medizin und der Naturwissenschaften (SGGMN) (Swiss Society for the History of Medicine and Natural Sciences) and the Schweizerische Gesellschaft für Logik und Philosophie der Wissenschaften (SGLPW) (Swiss Society for the Logic and Philosophy of Sciences). As there was for a long time no chair in the history of science in Switzerland the task of the national committee was limited to representing our country at the international congresses of the IUHPST.

The History of Science Colloquium was held every semester during thirty-five years as a public lecture series at the University of Zurich. ${ }^{7}$ It was organized by a group of professors and lecturers at the University and ETH Zurich who were interested in the history of science. The following professors or lecturers were among the founding members: Heinz Balmer (history of medicine and the natural sciences), Eduard Batschelet (mathematics), JeanFrançois Bergier (economic and social history), Markus Fierz and Klaus Hepp (physics),

\footnotetext{
${ }^{7}$ Three of the more than fifty lecture series have been published: 1. Die Blütezeit der arabischen Wissenschaft, ed. Heinz Balmer, \& Beat Glaus (Zürich: vdf Verlag der Fachvereine, 1990); 2. Wissenschaft, Gesellschaft und politische Macht, ed. Erwin Neuenschwander (Basel [etc.]: Birkhäuser Verlag, 1993); 3. Wissenschaft zwischen Qualitas und Quantitas, ed. Erwin Neuenschwander (Basel [etc.]: Birkhäuser Verlag, 2003).
} 
Gerhard Huber (philosophy), Peter J. Huber (mathematics), Karl A. Hünermann (paleontology), Huldrych M. Koelbing (history of medicine), Emil Kuhn-Schnyder (paleontology), Erwin Neuenschwander (history of mathematics), Herbert Sprenger (history of technology), Rudolf Trümpy (geology), and Bartel Leendert van der Waerden (mathematics and history of exact sciences). Later on, they were, among others, joined by: André Dreiding (chemistry), Helmut Holzhey (philosophy), Günther Rasche and Günter Scharf (physics), Peter Schulthess (philosophy), Ambros Speiser (technology), Vincent Ziswiler (zoology), and after 1997 for a while also by Gerd Folkers (pharmaceutics) and David Gugerli (history of technology). Beat Glaus and Yvonne Voegeli, historians and archivists at the History of Science Collections at the ETH, played a vital role as the persons responsible for secretarial duties and practical things.

My contacts with the representatives of the various fields of study in the Academy of Sciences (SCNAT) and in the organizing committee of the Zurich History of Science Colloquium enabled me-though working in the history of the exact sciences - to develop the keyword lists in the subject areas for which Heinz Balmer had been responsible. At first, I set up a provisional overall list for chemistry and the bio- and geosciences by extracting from the existing overall list made by the HDS the already included keywords and subsequently by supplementing these by searching appropriate lexicons and encyclopedias. The revised list was afterwards submitted to the experts in the respective fields for appraisal, as had been done in mathematics, astronomy and physics.

At my suggestion, already in summer 1996, a working group on geology led by the geologist Rudolf Trümpy was set up, consisting of Albert V. Carozzi (Urbana-Champaign, IL, USA), Sibylle Franks (History of Science Collections at the ETH library), Henri Masson (Lausanne), Jean-Paul Schaer (Neuchâtel), and myself. In June 1996, Trümpy compiled a provisional list of geologists based on the list of natural scientists that I had extracted from the HDS list. He then sought to rate the geologists mentioned in this list: A for "very important," B for "important," C for "less important" and D for "not to be included in the HDS." Then, he sent this list to the members of the working group. Their comments were considered and inserted into an updated version in July 1996. After a meeting with the working group in October, Trümpy sent me a third, almost definitive list. In the end, this procedure led to 22 new entries and 10 cancellations in the field of geology, which I transmitted together with eighteen additional new proposals to the editor in chief Jorio in December 1996. Trümpy's contribution was crucial to the precise representation of geology in the HDS. After having set up the list of geologists, he wrote a substantial article on "geology" and was very helpful in assigning articles to the authors and revising them.

The keyword list in chemistry - an important economic factor in Switzerland-had to be dealt with as carefully and broadly as the list on geology. In this respect, the former editor in chief of Helvetica Chimica Acta, Dr. Volkan Kisakürek, made an outstanding contribution. He had published together with Professor Edgar Heilbronner the comprehensive volume Highlights of Chemistry: as mirrored in Helvetica Chimica Acta (1994) which amounts to 985 pages. He was thereby one of the best experts in Swiss history of chemistry. In summer 1996, Kisakürek composed a six-page list of chemists who in his view definitely ought to be included in the HDS. Subsequently, I transferred the list to the expert group on chemistry together with my extracts from the overall keyword list of the HDS. As a first step, all winners 
of the Swiss-based Marcel Benoist Prize, and eleven widely known chemists were admitted. Subsequently more detailed proposals of cancellations and additions were made based on the feedback of the experts and on the practice of admission in the SL, NDB, and the DSB. The proposals were then again submitted to the experts on 8 February 81997 for secret ballots. This led in summer 1997 to the admission of twenty new chemists. At the same time, ten formerly included chemists were proposed to be removed by the experts.

The list of keywords in botany was perfected by applying the same procedures. I paid special attention to this list since I intended to write the main article on the subject. On the occasion of the centennial of the Swiss Botanical Society the journal Botanica Helvetica (vol. 100, 1990, issue 3) published nine detailed articles summarizing the development of botany at Swiss university institutes and botanical gardens. This substantially facilitated the writing of such an article also for the non-botanist. After having inserted the numerous proposals from the expert group on botany in my list of botanists, the central editorial office accepted in a first round those four new botanists who received the highest number of votes from the experts. From a list which Professor Maurice Burdet (University of Geneva) had sent to me, and which contained the names of approximately two hundred Swiss botanists, in a second step - after I had urged the central editorial office to reconsider their decision-an additional twenty to thirty scholars were authorized to be admitted. Therefore, I invited the members of the expert group in botany, including Professor Urs Boschung and Heinz Balmer, to undertake a second vote, which led to twenty-seven new assignments and eight cancellations. As far as I can remember, Professors Elias Landolt and Heinrich Zoller were of great help in the area of botany. I met Zoller once or twice in Basel, and the HDS has Landolt to thank for the excellent article on flora.

I did not have to worry as much about the list of keywords in zoology, entomology, mineralogy, or geography. In these fields, the authors of the main subject articles - being both experts in their scientific fields and in their historical development-in collaboration with me contributed to the perfection of the list of keywords. Professor Vincent Ziswiler, author of the main subject articles on biology and zoology, sought to enlarge the list of keywords in these two disciplines. Regarding the entomological research that had been widespread during the past centuries, I could rely on Professor Willi Sauter, for paleontology I could call on Professor Hans Rieber, and in the case of mineralogy on Professor Walter F. Oberholzer. Basically, I kept two main separate lists of keywords: one for mathematics, astronomy, and physics, and a second one for chemistry, bio- and geosciences. All additions were successively inserted into these two lists from which I often extracted special lists when working in the respective sciences as, for example, with the chronologically ordered list for the article on botany. According to my digitally stored and partly printed text files, the oldest preserved version of the second main keyword list originates from the 30 July 1996 and the latest from 3 February 2006, whereby the number of pages increased from twenty-six to thirty-eight which indicates roughly the extent and the period of time of the work done. 


\section{Development of suitable research infrastructures}

As I noticed with the first articles I had to review, many of the manuscripts written before my assumption of office were seriously flawed. For example, in the article on the mathematician Paul Bernays (1888-1977), several details concerning his career were wrong, and the references were incomplete. Bernays held indeed, as of 1934, lectures at the ETH Zurich, but contrary to the opinion of the author of the HDS-biography, it was only in 1939, and not in 1934, that he was appointed "Privatdozent" (Associate Professor). This emerged from the minutes of the ETH Council ("Schulratsprotokolle") which are now available online. Similar mistakes were to be found in respect to Bernays' career at the University of Zurich, as investigations at the University Archives showed. Of course, it was not the duty of a scientific advisor-according to the central editorial office of the HDS-to check scrupulously all the data in the more than 1,000 articles in one's subject area. One could refer the flawed articles to the editorial office to be revised. However, this could not ensure the elimination of all the mistakes, as can be seen again from the article on Bernays. In the HDS print edition we still find the wrong assertion that Bernays wrote a seven-volume work entitled A System of Axiomatic Set Theory (1937-54). In truth, the work in question is a series of articles in seven parts, which appeared in the Journal of Symbolic Logic. It was not until 1958 that the series was combined and published by the North-Holland Publishing Company in Amsterdam in book form under the title Axiomatic Set Theory. I also rejected, on 14 July 14 1999, the article on the astronomer Jean Alfred Gautier (1793-1881) from Geneva, since the references were flawed and incomplete. It was later on revised, without my participation, by the editorial office or by the author. However, they failed to correct the date of birth and the completely wrong statement that the well-known Zurich astronomer and historian of science Rudolf Wolf (18161893) was a German.

This is not the place to list all the mistakes and flaws in the articles I reviewed within the last twenty years. However, as responsible scientific advisor and president of the NC IUHPST at the SCNAT I felt obliged to look for ways to improve the quality of the articles about the natural sciences in the HDS. Therefore, in December 1995 I described the problems in a letter to the chief editor Marco Jorio and remarked that it was highly problematical to assign the articles on the most renowned Swiss mathematicians and scientists of the twentieth century to scholars not having any knowledge about the natural sciences in question. I suggested that for such an ambitious project as the HDS all four Swiss academies ought to be involved.

I also advocated an increase in lines of space for the main subject articles on astronomy and physics, which had at first been assigned only seventy lines, whereas astronomy alone in the smaller six-volume Swiss Lexicon 91 occupied three times as much space. In order to review the article on spaceflight (Raumfahrt) - which had already been assigned to an author and written before I assumed editorship of the natural sciences - I recommended that it be submitted for review to Professor Hans Balsiger, former president of the Science Programme Committee of the European Space Association (ESA), and one of the renowned experts in this field. Professor Balsiger reported that the article was "incomplete, unsystematic, imprecise," and "could not be saved." Fortunately, the editorial office commissioned another author to write a new article, which Professor Balsiger fully approved. Two years later a similar situation arose concerning the article on chemistry written by an 
historian. Hans-Jürgen Hansen, full professor of organic chemistry at the University of Zurich, stated in his report that the article was considered "even in the light of its imposed shortness (62 lines) very weak and in no way suitable, in a 'work for half a century' as the HDS would be, to represent the historical development of chemistry in Switzerland according to the current significance of chemistry." He added, "The essay consists, strictly speaking of a mere juxtaposition of platitudes without any historical underpinnings. [...] However, the editorial office of the HDS must be aware of the following, namely, that the field of chemistry, which is so important for the economy of the country, and therefore also important for the history of science and cultural history, cannot be treated in the space of 62 lines. It needs more [space], otherwise superficiality is foreseeable." Professor Tamm, former director of the Institute of Organic Chemistry and rector of the University of Basel, concurred in this judgment. These reports achieved their intended impact. Professor Hansen was chosen as the new author of the main subject articles on chemistry and chemical industry, and he also wrote numerous excellent biographies of chemists for the HDS.

For the very short 15-line HDS biographies, however, competent authors were often difficult to find. Scientists often shied away from having to gather the relevant biographical data requested by the HDS (place and date of birth and of death; year of marriage; place of citizenship; religious affiliation; name of father, mother, wife/wives and fathers-in-law; academic career dates, honors, etc.). Nor were they content with the fact that, in the end, there remained only three to four lines to sum up the scientific achievements of their earlier colleagues. On the other hand, established historians did not like to sacrifice their time writing short biographies by the dozen. Therefore, the HDS had to assign the short biographies to young historians who often wrote the articles without carefully investigating all the sources, even though the HDS paid them at a higher fee to safeguard their livelihood. There were some exceptions among these authors: Karin Marti-Weissenbach, who wrote in my subject area, contributed about one hundred biographical articles of excellent quality. On the other hand, it must be emphasized that in the HDS, in contrast to other national biographies, the amount of space was extremely limited. Aside from its role as a national biography, the HDS also served as a dictionary on Swiss subject areas and on Swiss townships and geographical entities. It followed in this respect the path of its predecessor, the Historical-Biographical Dictionary of Switzerland (HBLS).

In order to remedy the above-mentioned shortcomings, it did not suffice that the responsible scientific advisor-although critically but only summarily - looked at the relevant manuscripts and certified their acceptance by signing the article's dossier. Even experts sometimes fail to recognize immediately all the mistakes when reading a manuscript, since memory has its limits. Inaccuracies can usually be found only through a thorough study of the relevant literature, as was seen repeatedly in the course of editing. When one discovers conflicting statements, one has to return to the sources in the archives, registry offices, or wherever they are. Systematic work on the secondary literature requires one to search the online library catalogues, databases and search engines, and sometimes to consult catalogues and books on-site in the libraries themselves. For a small article of about 15 lines, this often imposed a heavy workload, from which many authors shied away, but then the responsible scientific advisor was forced to take over this task. 
These problems concerning the short biographies increased the responsibilities I had inherited after taking over the subject areas from which Heinz Balmer had resigned. I tried to obtain a grant from the SCNAT (at that time still called SANW) to employ assistants in order to adequately cover my by now huge subject area, "mathematics/natural sciences," which I could no more master on a part-time basis. Therefore, I wrote in the spring of 1996 to the president of the SCNAT and to its general secretary, asking them to support my research project, since I considered it important for the natural sciences to be represented adequately in the 100-million-francs project of the HDS. The SCNAT planned to give me an annual research credit (of about 5,000 Swiss francs), which they subsequently did not grant because of a problem of fields of competence between the SCNAT and the Swiss Academy of Humanities and Social Sciences (SAGW). I then reverted to the HDS which, however, could not dispose of any funds either to support-beyond the relatively small remunerations of the scientific advisors and authors - the institutionally hardly established research in the Swiss history of science. Requests for funds from the Swiss National Science Foundation (SNF) also failed at first because of conflicting fields of competence: the SNF was willing to support my own Riemann project but not the research in the history of science that I did for the HDS. According to the SNF, that research was the responsibility of the HDS, to which the federal government had given vast funds that the HDS was already disposing of.

To make a long story short - the Gerold and Niklaus Schnitter Fund for history of technology finally offered me in 1996 a grant (of 5,000 Swiss francs) after having discussed the matter with Professor Jean-François Bergier, who was also a member of the board of the Zurich History of Science Colloquium. Thanks to this grant, I organized a HDS working group during my seminar on the history of science in winter term 1996/1997. After I presented a detailed introduction to research techniques in the history of science, I initially allowed seminar participants to verify for themselves a few biographical articles, and later on to write articles as well. Further conversations with the members of the board of the Zurich History of Science Colloquium in spring 1997 led to an interview with the rector of the ETH Zurich, Professor Konrad Osterwalder, in the presence of Professor Gerd Folkers, long-standing director of the Collegium Helveticum. I explained to them the problems I encountered while continuing to represent the history of science faithfully in the HDS as well.

In these discussions, I found understanding, but neither administrator could offer long-term support. By virtue of my comments on frequent mistakes, Dr. Jorio became aware of the urgent need for action. The HDS at the time was in a difficult position, since nothing had been published during a period of ten years. The HDS board thereupon decided that, for the time being, priority was to be given to the electronic publication (Figure 3) of a number of already edited articles rather than wait for the printed version of all the articles of volume 1 . The Swiss newspaper, Tages-Anzeiger, published the news as its lead story under the sensational title, "60 Million of Government Funding for a Lexicon." The story was illustrated with a caricature by "Nico" (Klaus Peter Cadsky) depicting a tomb and carrying the legend, "I am sorry about that, but the tombstone alone costs 60 million." ${ }^{8}$

${ }^{8}$ Cf. SonntagsZeitung, 26.10.1997, and Tages-Anzeiger, 7.9.1998. 


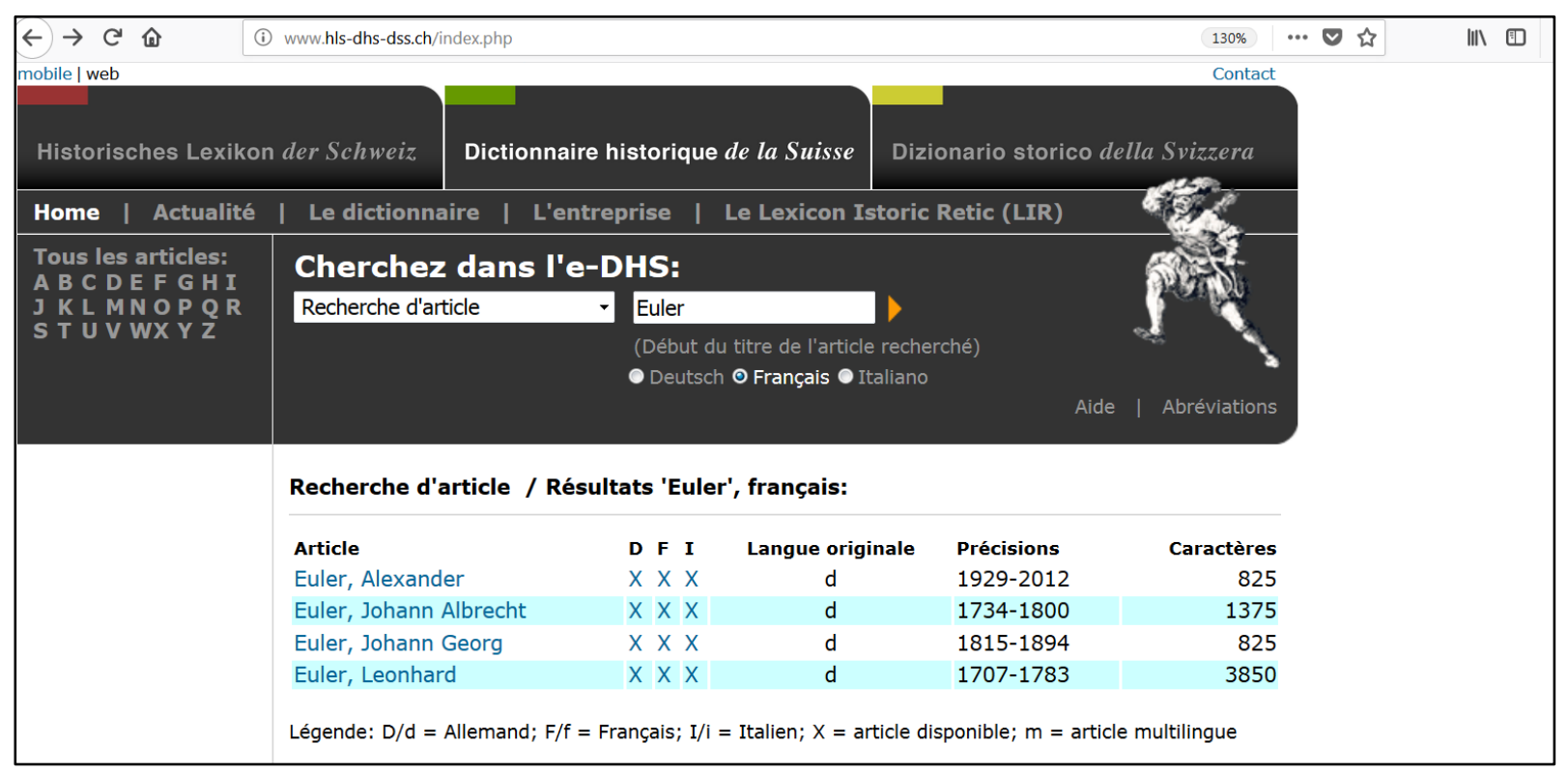

Fig. 3 Entry page of the online version of the Historical Dictionary of Switzerland with the results for the search term "Euler"

In order to improve the situation, Dr. Jorio invited me in his letter of 18 May 1998 to draft a rough plan for a better handling of biographical articles in the subject area of natural sciences. We worked on it together, and we first pointed out that the historiography of science in Switzerland had a remarkable tradition that extended back to the nineteenth century, and that it was closely connected with the Naturalist Societies (Naturforschende Gesellschaften) then springing up, and with the historiographical studies of ETH astronomer Rudolf Wolf (18161893). Unfortunately, Switzerland was not able to maintain this level since it did not join in the worldwide institutionalization of the discipline. To our joint draft, Dr. Jorio added that the history of science as well as the related history of technology remained a cause of great concern. He pointed out that the central editorial office had fallen back on general historians out of necessity, and that the result was not satisfactory. If this situation could not be changed by trying to get specialist authors to write these articles, the history of science threatened to become the great weakness of the new HDS.

He then proposed that the problem be resolved by dividing the labor between historians and scientists - as had been done for years at the New German Biography (NDB): "Professor Neuenschwander and his team ensure the research of the bio-bibliographical data-not known to the science community - of the articles. He reviews all the incoming articles and maintains the contacts between the scientific authors, the assistants and the central editorial office, whereas the writing of the articles rests with suitable natural scientists." Dr. Jorio also set up a detailed working plan and budget. The costs for the plan were to be borne jointly by the HDS, the University of Zurich, the ETH Zurich, and the SCNAT. The HDS would have to contribute the fees to the authors (650 articles at an average of 20 lines per article, and at the rate of 5 Swiss francs per line), i.e. 65,000 francs. The University of Zurich would pay the cost of the infrastructure; the ETH Zurich would contribute an operating credit for 
Professor Neuenschwander; and the SCNAT would pay the costs for the assistants at the rate of 8,750 francs per year for six years, a total of about 52,000 francs.

The SCNAT received Dr. Jorio's August 1998 proposal with great interest, and subsequently granted a framework credit of 8,000 francs per year on condition that the other three potential sponsoring bodies (HDS, University of Zurich, and ETH Zurich) also participated. The responsibility and control of the work was to be provided by the president of the Swiss Society for the History of Medicine and Sciences (SGGMN), Professor Urs Boschung. Dr. Jorio then created a working group called, "Project Swiss Natural Scientists" (Projekt Schweizer Naturwissenschafter), consisting of Urs Boschung, Marco Jorio, Erwin Neuenschwander and Rudolf Mumenthaler (at that time head of the History of Science Collections at the ETH Zurich and scientific advisor for technology at the HDS). The four of us were to coordinate the administration of the SCNAT money and the further works. Our first meeting was in Berne on November 24 $4^{\text {th }}, 1998$, and thereafter we met twice a year until autumn 2007. One of our first tasks was to review and coordinate the four lists of biographies that the HDS sent us: Medicine, Scholars of the Middle Ages and Early Modern Era, Scientists of the Nineteenth and Twentieth Centuries, and Engineers/Technicians). In order to cope with this task, I prepared an 8-page list with comments, and requested to consider me as second examiner for relevant biographies not yet categorized within my range of responsibilities. Furthermore, it was decided to cooperate more closely with the ETH Zurich University Archives and its collection named "Biographical Files."

In December 1998, Dr. Jorio wrote to Hans Werner Tobler, Professor of history at the ETH Zurich, to obtain the required operating credit funds (crédit de fonctionnement) for myself, as the SCNAT made the further payment of their money dependent on the collaboration of the ETHZ and the University of Zurich. To advance more rapidly, I organized a new working group. It consisted of, among others, Martin Kurz, who worked for the HDS in the following years, and of Adrian Bosshard, who joined me in writing an article documenting all Swiss Nobel prize laureates for the Swiss Science Council (Schweizerischer Wissenschaftsrat), to be published in the journal Futura. In the meantime, the institutional situation at the University of Zurich continued to improve. Professor Vincent Ziswiler was then dean of the Faculty of Science (MNF). He was deeply interested in the history of science and also long-time head of the board of the Zurich History of Science Colloquium. In 2000 he arranged that the faculty established a cost center for history of natural sciences with an annual credit of 10,000 francs. Professor Kurt Brassel, his successor as dean, created for me in 2001 a part-time position under the direct authority of the Dean's Office of the MNF. Our working group colleague, Professor Boschung, generously accepted the administrative management of a redesigned HDS research project to the SNF entitled "Contributions to the History of Sciences in Switzerland (Biographies and Subject Articles)." Dr. Jorio co-signed the proposal and they both submitted it to the SNF on 27 February 2001. It stipulated another part-time position for me at the University of Berne, and it included funds for a scientific assistant, Martin Kurz. Initially the project was for a period of three years from 2001 to 2004, but it was prolonged, without incurring additional costs for the SNF, until 2005. In autumn 2004, Professor Boschung submitted a renewal application for the period of 2005-2007. When I retired, I applied for a further extension for the years 2007-2011, which would support the part-time employment of my new collaborator, Dr. Christian Baertschi. The time remaining until the completion of the 
HDS print edition could be bridged by new minor credits from the SCNAT and the MNF, and these funds enabled me to retain Dr. Baertschi until the end of the project.

With all these actions, the editing and review of the natural sciences in the HDS was placed on a solid basis nearly up to the publication of the final volume, the 13th, in 2014 . As director of the small research center for the history of the natural sciences at the University of Zürich, and with an almost full-time position at the Universities of Zurich, Bern and ETH, I could for the first time do research in the history of science on a solid institutional basis. The institutional credit, which was later increased, supported the part-time employment of my collaborators Christian Baertschi and Martin Kurz, the purchase of computers and of important literature, as well as the travel to conferences, including organizing and financially supporting some of them myself. Without the extraordinary organizational skills of Dr. Jorio, the scholarly commitment of Professor Boschung, as well as the support from all the professors interested in the history of science at both Zurich universities, all this would not have been possible. I therefore express my deep gratitude to all the persons involved.

\section{Normal procedures, results and remaining problems of implementing the scientific review}

For twenty years, producing the articles in all areas of the HDS, including those in the natural sciences, followed the same procedure, step by step. The person responsible for a certain step had to record and sign its fulfilment on the cover of the relevant dossier (Figure 4). First, the empty blue dossier was sent to the author whom the scientific advisor or the central editorial office had designated. When the author returned the finished manuscript, the chief editor or one of the heads of the German, the French, or the Italian editorial team looked at it briefly, and then sent the manuscript to the scientific advisors for their review. The manuscript was then returned to the central editorial office, where it was edited, shortened and made conform to the format of the HDS. Subsequently the article's author got a galley proof. In the final step, the article was translated into the other two main languages of Switzerland. Although the articles were worked on in alphabetical order, years often passed between the steps. 


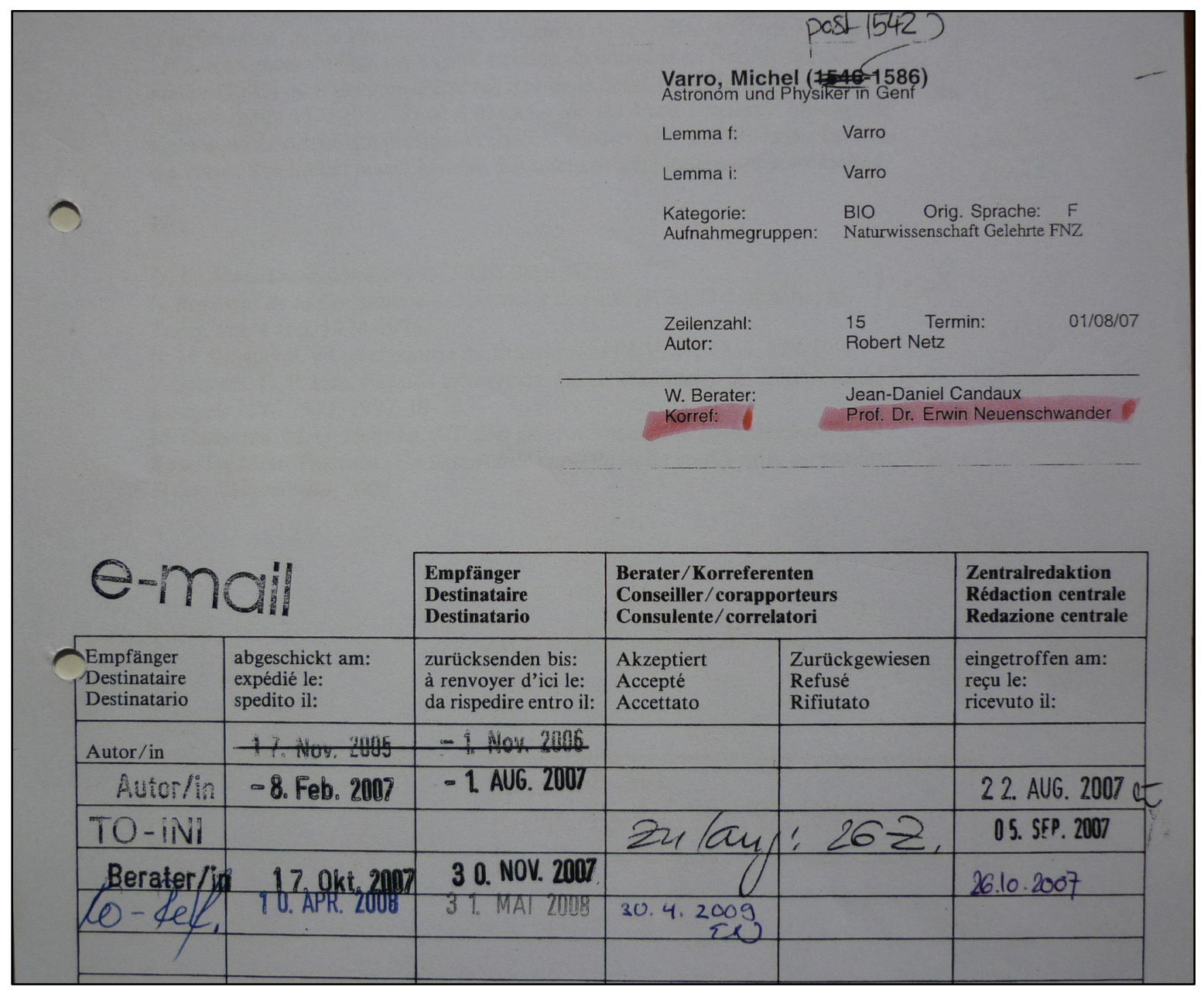

Fig. 4 Section of cardboard folder for the HDS-dossier "Varro, Michel"

The allocation of the articles to the authors was usually done for two or three volumes all at one time. As a scientific advisor, I received a list containing the articles for which the authors had not yet been found. I would send the list to experts and authors in my areas of study to let them choose the articles they wanted to take over. They often suggested additional persons whom they thought capable of writing a specific article. I then sent the completed list back to the central editorial office, together with the suggestions about suitable authors that I had collected. The central editorial office thereupon concluded contracts with all those authors. Because there were always some articles for which no author could be found, the members of my working group at the University of Zurich or the members of the central editorial office in Berne would write them instead.

Basically, I tried to find a well-known scientific expert for each article, since profound knowledge in his area of study guaranteed an informed and accurate appreciation of a scientist's work. On the other hand, natural scientists are not trained historians, so their articles often missed some of the biographical data and were sketchy in the secondary literature, which had then to be researched and added by the scientific advisor. This made me 
write-contrary to my original intention-some of the more important articles in the later volumes myself to avoid additional work in the final steps of the editorial process. That was the major reason why I wrote the main articles on botany, mathematics and physics, and several important biographical entries in my own fields of study.

In order to make the authors' work easier and to improve the articles, we developed various tools. In 1996, chief editor Marco Jorio and I wrote "Instructions for biographical articles in the area of natural sciences of the HDS," which the authors received with their contract. The instruction sheet contained concise guidance on how best to write an article, and a list of the most important research tools and methods in the area of Swiss history of science (useful library catalogues, databases, encyclopedias, secondary literature, and so on). Due to the tightening of the data protection regulations, it became more and more difficult for an author to obtain the required biographical data (date and place of birth/death, place of citizenship, religious affiliation, name of parents, spouses, etc.). Therefore, in cooperation with the federal authorities Dr. Jorio created a short documentation and a questionnaire, which were handed out to the authors. Authors could send this to the relevant registry office (Zivilstandsamt) in order to authenticate them to obtain the required biographical data.

For reviewing and selecting the secondary literature in the HDS biographies, the project "Swiss Natural Scientists" (Schweizer Naturwissenschafter) was of prime importance. Working within the framework of this project, we systematically searched the two biographical catalogues at the Swiss National Library. Then copied out the filing cards that contained bibliographical records on a natural scientist and compiled the findings for each scientist on a single sheet of paper. This documentation should make the work of the HDS authors and of the scientific advisors easier. At the same time, we also looked through the extremely valuable collection of about 1,500 biographies of natural scientists in the Verhandlungen der Schweizerischen Naturforschenden Gesellschaft (1817-1977) (Proceedings of the Swiss Naturalists Society), the commemorative publications of Swiss universities (e.g. the especially broad and comprehensive six-volume publication Le livre du recteur de l'Académie de Genève, 1959-1980), as well as several other encyclopedias and lexicons of Switzerland.

In order to thoroughly review the articles submitted by the authors about scientists, we first searched the discovery tools and online catalogues of Swiss libraries (Swissbib, NEBIS research, Knowledge Portal ETHZ, RERO explore, Sbt, etc.), as well as other useful online databases and search engines (especially Google) for more biographical information and secondary literature. We then compared the results with the author's text and tried to reconcile the differences through further research in the literature, in libraries and in archives as well. We then added these alterations into the manuscript, and wrote a report to the central editorial office, describing and documenting all the necessary changes for every article.

These reports had several objectives: they intended to inform and document our corrections and additions, first to the central editorial office, second to the author, and third to compile our material and results for the History of Science Collections at the ETH Zurich. The final purpose these reports served was to become the annual reports of our activities, which our sponsors (e.g., SCNAT and SNF) required since 1999, when the SCNAT sponsoring began. We sent the reports of our corrections and additions to the central editorial office in packages of a dozen at a time together with the corrected articles, and at the end of the year 
we collected and rearranged these reports in alphabetical order as our statement of accounts (often about 30 pages long) to our sponsors. This comprehensive documentation of our work during the last fifteen years 1999-2014 may be of use for subsequent historical studies on these same scientists.

Despite all our efforts, the quality of the authors' articles did not improve as significantly as we had hoped: we still had to make substantial corrections and to supplement the secondary literature during the scientific review. Describing some of the most frequent problems will further illuminate our procedures. During the editing process at the central editorial office, the articles were often shortened, and rewritten. Sometimes these changes altered the actual content of the article, turning a given statement into an erroneous one. Authors were understandably upset, and the scientific advisor responsible for reviewing the article was never informed about such changes or about the suggestions of participating coadvisors. For example, Professor Srishti D. Chatterji wrote a beautiful article on Armand Borel (1923-2003), the well-known mathematician. Unknown to me the article was shortened significantly by the central editorial office and new mistakes were made: the term "algebraische und arithmetische Gruppen" was changed to "algebraische und mathematische Gruppen," and in order to shorten the article the author's extensive list of Borel's many honors was crossed out completely. Much later, the central editorial office asked me whether the Balzan Prize should be mentioned in the article on Borel, even though they themselves had earlier crossed it out. Chatterji was understandably not pleased about the affair and never wrote an article for the HDS again.

When the HDS was first planned, every area of study was assigned a certain number of lines. Because the area of mathematics and natural sciences was not then represented by a scientific advisor, the number of lines allotted to these subjects was small. Authors of articles had to fight for the necessary space in order to give an adequate account of their subject. For instance, the article on chemistry, which is very important for the Swiss national economy, was fobbed off with just 62 lines, and the articles on mathematics and physics were originally given only 80 lines. As a scientific advisor, it was my duty to argue on behalf of these authors for more lines so that they could fit a maximum of information into a reasonably increased minimum of lines. From the standpoint of the central office, it was difficult to allow more lines of print while the project was already being undertaken, and at the same time maintain the number of pages and of volumes as originally planned. Nevertheless, I always followed the advice of Heinz Balmer: "Write the articles as they have to be written!" Part of the duty of the central editorial office, of course, was to shorten articles, but their shortenings had to be negotiated and limited. In some cases, I refused to sign the shortened articles, so the central editorial office either cancelled them totally or signed them itself.

To ensure the quality of the articles in the area of natural sciences, I decided to check them again voluntarily, beginning with volume two, after the editorial process had ended but before the actual printing begun. I could do so because the articles were placed on the internet in packages before the actual printing was begun. I marked the additions which the central editorial office had not yet included, and indicated new mistakes. The central editorial office initially disliked what I did, because making changes so close to printing was expensive. However, there was no better time to correct these mistakes, because most of them occurred only in the final process of editing, and after the scientific review. Although the translations of 
some articles into the two other national languages were flawed or imprecise, I checked only those of my own articles since the responsibilities of a scientific advisor were already great enough, and being a translator was certainly not among them.

Finally, I would like to state, that our effort on behalf of the history of natural sciences in the HDS during the past twenty years achieved decisive improvements. The number of the articles and the line-space allotted to them in the area of natural sciences was significantly increased. More than a hundred articles on natural scientists, and new articles on subject areas such as biochemistry, entomology, and microbiology were added. Our studies in the archives closed several research gaps and corrected numerous mistakes. Our collected documentation of working documents spans about five running meters, and attests to our contribution to the articles published in the HDS. We hope that with the publication of a one-volume German print edition in 2018 (Schwabe, Basel) and with the probable inclusion of our results in the "New HDS" and Wikipedia our research will be of use to the international community in the future.

Thanks to Dr. Jorio, there were also some relaxed and sociable moments in the life of one who contributed to the HDS. Every year the new volume was presented to the public at a vernissage. It usually took place in one of the Swiss cantons concerning which the new volume contained the main cantonal article. Members of the local government were invited, as were the press, the scientific advisors, and the authors. More than a hundred people usually attended these vernissages, and they offered excellent opportunities for meeting colleagues and exchanging ideas. The first vernissage took place on October 30 3002 in Berne, the last on 24 October 2014 in Zurich. Side-vernissages were also held in all the other cantons that had their main article in the then-current volume. One of the last celebrations took place on 17 November 2014 in Zug, where Marco Jorio grew up and attended its schools. The special charm of that day was that it taught one something more personal about the history of the HDS and some further details about the life of its chief editor. Before these vernissages took place, Dr. Jorio had invited the scientific advisors to a congress in the hotel Alfa in Berne every second year.

To Dr. Jorio belong special honors for his contributions to the great project of the HDS. Through his extensive network of colleagues and friends, he won the support of influential politicians and secured the funds needed for the project. His austere discipline enabled him to publish one volume every year since 2002 in all three major national languages, thereby completing the entire project on time by autumn 2014. For his meritorious contributions to the HDS, the University of Berne bestowed on Marco Jorio an honorary doctorate in 2015. 
Towards a Swiss historical information system based on a linked data and multimedia approach: the new HDS, Metagrid, and the Encyclopaedia for the History of the Natural Sciences in Switzerland ${ }^{9}$

After the completion of the print edition of the HDS in 2014, our working group started to update the partially twenty-year-old HDS articles. For the bicentenary of the Swiss Academy of Sciences, our purpose was to publish a memorial volume containing all the HDS articles on natural sciences in an updated version that should be ready by 2018. Beginning at the same time, the editorial staff of the HDS started transforming the database for the print version into a full-fledged research infrastructure, offering features that are now commonly used in state-of-the-art online databases. The new multimedia site will incorporate all kinds of audio-visual historical documentation by importing in a first step all the illustrations and infographics of the print version. Later it will aim to integrate on a large scale the interactive electronic resources from libraries, archives and museums, and from further reliable cultural institutions. Such a truly networked, interoperable Swiss humanities information system allows queries of otherwise unmanageably big data volumes, including geo- and chronoreferenced, medium-specific and subject-based queries, and also combinations of these. The metadata play an even more crucial role than before, because-for example-the audio-visual material is also indexed in several languages. One key feature of this far-reaching transformation will be the implementation of multilateral links, e.g. to the Bibliography on Swiss History (BSH).

BSH Volumes 1913-1974 of the print edition were scanned using Optical Character Recognition (OCR), structured, and uploaded to the e-periodica.ch website. Full text searching may be carried out both across a selected range of volumes, or across all volumes simultaneously. In addition, within each volume it is possible to go directly to a specific chapter. The BSH volumes from 1975 onwards are available in the BSH database, which has been in existence since 1999. Volumes 1975-1998 were re-catalogued in 2010 and integrated in the database. Initially, the chapter structure of the years 1975-1998 was not the same as that for the years 1999-2010, but they have subsequently been unified. In 2012, the classification of the 87,000 bibliographic records in the BSH database was adapted on the basis of the Dewey Decimal Classification (DDC). It was decided to abandon subject-heading strings. Most of the keywords were replaced by GND (Gemeinsame Normdatei / Integrated Authority File) descriptors - operated cooperatively by the German National Library. The use of GND in the BSH Database was a prerequisite to allow linking with other online resources as the Historical Dictionary of Switzerland, using also these authorities. The persistent identifiers in the metadata (VIAF and GND numbers) are-amongst others-especially needed to enable the (semi-)automatization of linking. By clicking on the personal name heading in the bibliographical record, in the near future the user will obtain the corresponding article on that

\footnotetext{
${ }^{9}$ For further details and information about these recent developments see in particular Sacha Zala, \& Christiane Sibille, "Metagrid und die Vernetzung von Metadaten," Arbido 2017/3; Nathalie Vuilleumier, \& Werner Bosshard, "The Use of the Bibliography on Swiss History for Electronic Historical Resources; The Example of the Historical Dictionary of Switzerland," in Historical Bibliography as an Essential Source for Historiography, ed. Kristina Rexová et al. (Newcastle upon Tyne: Cambridge Scholars Publishing, 2015), 193-206; as well as Peter Haber, “Die Vision eines e-HLS der Zukunft," in Eggs \& Jorio, 135-47.
} 
person in the HDS, and he will have access to all the other references and links indicated in that article. The grid-computational work will be provided by the Swiss web service Metagrid.

Metagrid.ch is a project by the Swiss Academy of Humanities and Social Sciences (SAGW) for an online network of resources of the humanities, executed by the Diplomatic Documents of Switzerland (DDS: dodis.ch) with support of the Historical Dictionary of Switzerland. The official kick-off event of the Metagrid project took place on 19 June 2015 at the Swiss National Library in Berne. Current partners, or linked databases are, among others-besides the Diplomatic Documents of Switzerland, the HDS and the BSH-the following databases: "Elites suisses aux XXe siècle" of the University of Lausanne, the US Department of State-Office of the Historian, the German National Library's Authority File (GND), the League of Nations Search Engine (Lonsea), and the Swiss National Library with its catalogue "Helveticat". Future partners may include, for example, the e-periodica project, which aims at the digitisation of Swiss scientific and cultural journals, HelveticArchives-the database maintaining the bibliographical records of the archival collections of the Swiss National Library, editions of the works of Swiss scientists, etc.

With regard to our past symposium in Prague about prosopography, ${ }^{10}$ it should be pointed out that the New HDS intends to expand its biographies and family articles by introducing a specific prosopographic perspective. Networks and personal relations will be opened up for navigation and research. Furthermore, data can be collected selectively by various referenced queries - as has already been said. Based on the Linked Open Data approach - here mainly established by Metagrid - person-related information can more easily be gathered and processed, even (semi-) automatically, and without having to disambiguate names of persons. The clearly standardized structure of the HDS biographical articles are such as to give the following content-related information: family relations, social origin and geographical and social mobility, citizenship, religious denominations, career lines, objects of research, affiliations, and so forth. The new HDS can ultimately be seen not only as an immense data pool for prosopography, but also as a more or less modern, but not yet fully processed prosopography in itself, and as part of a research infrastructure or laboratory to be used for studies about persons related to Switzerland - and even beyond, by adding foreign and transnational data sources.

${ }^{10} \mathrm{Cf}$. footnote in this article, on 96. For further information about prosopography see for example Katharine S.B. Keats-Rohan, ed., Prosopography Approaches and Applications: A Handbook (Oxford: Oxford University Press, 2007). 